\title{
Effects of Social Media Interaction on Self-Presentation among Students in Public Secondary Schools in Nairobi County, Kenya
}

\author{
Jecinta W. Muigai \\ Ph.D., \\ Department of Education, \\ School of Education, Arts and Social Sciences (SEAS), \\ Africa International University. Kenya
}

\begin{abstract}
As technology continues to expand, adolescents have embraced interaction through social media platforms. They interact through sharing comments, posting photos, profile updates, etc. Some of the social media platforms that adolescents use is Facebook, Twitter, WhatsApp, Snapchat, YouTube, among others. This article explored the effects of social media interaction on selfpresentation among adolescents in high schools in Nairobi County, Kenya. A descriptive survey design was used to understand the phenomenon. A questionnaire was used to collect data from the respondents. A sample size of 400 respondents was obtained through stratified random sampling and simple random sampling. SPSS version 20 was used to help analyze the data for descriptive statistics, and linear regression was used to predict the effect of social media interaction on the self-presentation. The regression model was significant $F(1,344)=38.618$, $p$-value <.05. Further, the $R$ Square $\left(R^{2}\right)=.101$ shows $10.1 \%$ of students' self-presentation can be attributed to social media interaction. The coefficient of the self-presentation based on the students' social media interaction showed the regression weight was statistically significant $(p<.05)$. The output showed social media interactions affect students' self-presentation $(\beta=.318, t=6.348, p<.05)$, hence an increase of social media interaction interrupts the students' self-presentation by .318. It is necessary to have seminars and workshops to educate the parents, teachers, youth workers and adolescents on these effects.
\end{abstract}

Keywords: Social Media, Interaction, Self-Presentation, Adolescents, Secondary School.

\section{INTRODUCTION}

Social media interaction has become the most popular thing among adolescents in the twenty-first century. This interaction takes place on platforms such as Facebook, Twitter, WhatsApp, Snapchat, YouTube, among others. Adolescents tend to seek their self-identity, establish, and maintained contacts through social media platforms. In the process of interacting, adolescents attempt to influence how other people view their image consciously or unconsciously through the information they present. Valkenburg and Peter (2011) viewed self-presentation as a conscious act in their definition when they stated that "selfpresentation can best be understood as selectively presenting aspects of one's self to others" (p. 122). That is, managing one's self-image using self-presentation tactics. In social interaction, people always attempt to present themselves in the best way they know.

As media technology continues to grow, the risk of adolescents engaging in excessive indulgence in social media is likely to occur, and in turn, may affect their self-identity and specifically the self-image they would want to present to other people. Selfpresentation can influence adolescents' self-esteem and self-concept clarity through the audience's feedback and self-reflection (Yang \& Brown, 2016). It is crucial for parents, teachers, and youth workers to understand the impact of social media platforms on adolescents' self-presentation that is dictated by the self-image adolescents desire to portray. Therefore, the purpose of this article was to explore the effects of social media interaction on self-presentation among high school students in public secondary schools in Nairobi County, Kenya. 


\section{RESEARCH OBJECTIVE}

Research question guiding the study is, how does social media interaction affect high school students' self-presentation?

\section{Self-presentation}

Every human being desires to make others see the image they positively present of themselves. Self-presentation also known as impression management is defined as "people's attempts to convey information about or images of themselves to others" (Gilbert, Fiske, \& Lindzey,1998, p. 703). Self-presentation is the act of trying to impress others to shape how they view them. The individual tries to impress others through their expressions, actions, and disclosure of information (Baumeister \& Hutton,1987). These acts are a means of projecting impressions in social interactions (Baumeister, 1982). Even though some aspects of these self-presentations are sometimes deliberate and conscious, others are not. Given that people can present false images of themselves, in general self-presentations are genuine attempts of an individual to present a positive self-image to others yet remaining authentic.

People engage in the act of self-presentation daily. Studies show that people take in self-presentation to raise their interactive worth and enhance social acceptance; they shape their expressions to influence other people for varied reasons. Thus, by displaying certain images of themselves, they can get help from other people, persuade others' submission, improve their financial status, avoid unpleasant tasks, do social roles more effectively, exact distress on others, and attain other personal and interpersonal benefits (Baumeister, 1982; Baumeister \& Hutton; 1987; Jones \& Pittman, 1982; Leary, 1995; Leary \& Kowalski, 1990; Schlenker, 1980).

Baumeister (1982) pointed out two main motivations of self-presentation as one, pleasing audience to match their expectations and preferences; and two, self-construction that has to do with matching one's self-presentation to one's ideal self. For instance, an individual may present him/herself as a model and so the individual may present a more likable and attractive image of him/herself. On other occasions, a person may want to present behaviors that make others see him/herself as a highlyskilled, more challenging, and tough person. People tend to make certain impressions on others to maintain one's connections with others and meet their identity needs. Jones and Pittman (1982) grouped the motivation to self-presentation into several tactics of impressing others that include: self-promotion, ingratiation, exemplification, intimidation, and supplication, as explained below. Self-promotion tactics is a state whereby a person seeks to convince others of the abilities he/she possesses; ingratiation is a selfpresentation tactic where a person does everything possible to seek to win other's favor; exemplification is a tactic by which individual self-sacrifice by doing more than expected to win other's approval; intimidation is a strategy employed to make others fearful; and lastly, supplication explain a situation where an individual brings out their weaknesses with an aim of getting support from others.

Self-presentation is enhanced by social interactions brought about by communication between individuals. As people interact with one another, there is a tendency to change their actions and response to impress their friends, peers, and so forth. The desire to manage impressions is also notable among adolescents whereby they try to take charge of how others see them by carefully presenting their self-image (Baumeister, 1982; Leary \& Kowalski, 1990). When self-presentation is done consciously, adolescents are keen and attentive to the self-image they want to portray (Livingstone \& Haddon, 2009; Baumeister, 1982; Perloff, 2014). The perception of who they are is influenced by the impressions they make about themselves. This present investigation assumed that self-presentation is affected by the interactions that adolescents engage in, in social media platforms as they seek their identity needs.

\section{SELF-PRESENTATION ON SOCIAL MEDIA PLATFORMS}

Several studies have explored the association between interactions and offline self-presentation (Goffman, 1959, Jones \& Pittman, 1982, Leary, 1995). For instance, Goffman (1959) asserted that human beings always struggle to impress others to view them as reputable and dependable as they also try to keep established desired positive self-image. According to Baumeister (1982), people use self-presentation to conceive their identity. In the contemporary world of advanced technology, adolescents are not only seeking to bring about their impressions face-to-face but also in social media platforms (Zhao, Grasmuck \& Martin, 2008). "Internet-based communication tools provide novel venues for self-disclosure, self-presentation, and impression management" (Rui \& Stefanone, 2013, p. 1286). Social media platforms satisfy the need for self-presentation in different ways as adolescents feel they have the freedom to interact with others away from parental control. Self-presentation on social media platforms takes place just like it happens on face-to-face through body language, posture, speech, status among other things.

Adolescents create their social media profiles and groups where the intended audiences receive or see the content they post. These photos, selfies, comments, and status are updated, edited, and modified to make some impressions on social media platforms. Through the feedback they receive such as "likes", and comments, adolescents evaluate what others say about them, and through their self-assessment, they edit their content based on the feedback and adjust to the desired self-image (Ho, Lee, \& Liao, 2016). According to Vohs, Ciarocco, and Baumeister (2005) self-presentation requires some adjustment and shaping of 
behavior to achieve a certain public image, meaning many active impression management responses are self-regulatory in nature. It is through social media platform interactions that adolescents perceive who they are and evaluate themselves with the feedback they receive. Baumeister (1998) emphasized that "most people have a certain ideal image of the person they would like to be. It is not enough merely to act like that person or to convince oneself that one resembles that person. Identity requires social validation" (705).

Adolescents may use the feedback to evaluate themselves positively or negatively. Metzler and Scheithauer (2017) conducted longitudinal research among 217 adolescents age 14-17 years to check on the impact of positive self-presentation and the number of friends on Facebook. They noted that adolescents' "positive self-presentation and several friends were associated with positive feedback" [7]. Yang and Brown (2016) surveyed 218 university first-year students to explore changes in their online self-presentation. The study also examined the link between online self-presentation and student's self-esteem and self-concept clarity. In their finding "Broad, deep, positive, and authentic Facebook self-presentation was positively associated with perceived support from the audience, which contributed to higher self-esteem..." (p.402).

On the contrary, self-presentation may be affected negatively if the feedback received is not interpreted positively. For instance, failure to get the expected "likes" or comments on the posts may lead to a poor view of self-image. Social comparison may also affect adolescents' views of their self-image. A study by Kleenmans, Dalmans, Carbaat, and Anschutz (2018) on the effects of manipulated Instagram photos amongst 144 girls aged 14-18 years old on girls' body image, asserted that exposure to controlled Instagram photos led to low body image, more so, girls inclined to too much social comparison were negatively affected. Deliberate Facebook self-presentation make students reflect inwardly, which can be linked to lower self-concept clarity (Yang \& Brown, 2016). Although positive feedback may affect self-presentation positively, it can lead to addictive behavior like excessive usage of social media (Meshi, Morawetz, \& Heekeren, 2013). That desire to make positive impressions is part of what makes adolescents spend a lot of time on social media platforms. They use much of their time changing pictures and information about themselves on social media platforms to present to others their most appealing self. When adolescents use social media platforms in trying to define who they are, they become very selective with the content they expose to others (Gabriel, 2014; Chua \& Chang, 2016). Adolescents are encouraged to edit their self-images when their presentation aid in gaining rewards and creating identities (Leary \& Kowalski, 1990; Yang \& Brown, 2016).

Another study by Gosenell, Britt, and Mckibben (2011) among 80 undergraduate students ages 18-25 in the USA examined the self-presentation concerning interaction and relationship satisfaction. They found that when the bond between adolescents and their peers is stronger, the lesser the attempts in self-presentation, and the higher the relationship fulfillment. On the contrary, the lesser the bond is with peers, the more the efforts in self-presentation and in turn increased relationship satisfaction.

The self-presentation can sometimes put into risk the lives of adolescents by exposing them to strangers who might have ill motives. Internet predators who may threaten adolescents through cyberbullying, or may target them for abuse (Steijn, 2014; Walrave \& Heirman, 2012). Self-presentation among adolescents needs to be carried out with care as it increases questions of privacy. Although there is an inclination for girls to exercise privacy of their profiles more than boys, as revealed in a study conducted by Patchin and Hinduja (2010) among 2423 teenagers' profiles. Rui and Stefanone (2013) looked at varied selfpresentation behaviors on social media by examining the impression motivation, self-worth, and social network structure among 248 undergraduate students surveyed. They discovered that respondents posted on their wall almost every few days and they also protected their self-presentation in response to unwanted photo tagging. Additionally, they found "individuals with large networks have increasing demands for relationship maintenance, which results in increased photo sharing" (Rui \& Stefanone, 2013, p.1301).

Wong (2012) examined the association of self-presentation to the use of Facebook and social support among 202 university students. The result showed that the frequency of Facebook usage was statistically significant and positively related to three types of self-presentation (ingratiation, supplication, and enhancement), additionally, Facebook usage as interaction with friends was statistically significant with self-presentation (p. 199). Further, Wong (2012) examined "relationship between selfpresentation and social support received on Facebook; results showed that three types of self-presentation were related to social support sought or received by students on Facebook" (p. 203).

Self-presentation does not only include the tactics of managing impressions but also multiple presentations of self. As adolescents explore their self-identity, they may present themselves in differing aspects. Aspects of self presented can differ depending on the audience present or imagined or circumstances present (Higgins;1989). That does not mean adolescents present false images of themselves, but different aspects of self can be displayed to different people and situations. For example, a teenager may present a different aspect of self to peers in a different way to how she presents to strangers or friends who know them. Higgins (1989) suggested that individuals think of themselves from two perspectives, that is, their viewpoint, and that of other significant people such as parents, peers, teachers among others.

The three aspects of self include a person's real self or actual self, ideal self, and ought self. A real self or actual self is a person's current self-concept or true views or beliefs one has of himself. An ideal self signifies beliefs about characteristics one desires to have, i.e., what one aims to become or what a significant other would like that person to be, and lastly ought self or 
public self, signify what a person believes he/she should be (Higgins, 1989). Michikyan, Dennis, and Subrahmanyam (2014) did a study among 261 emerging adults to examine their self-presentation on Facebook using a multiple self-presentation framework. The Multiple self-presentation framework was checking on "adults' presentation of their real self, ideal self, and false self" (p.1). The respondents reported that they presented their real selves more than their ideal self and false self on Facebook. However, those with "a less coherent sense of the self and lower self-esteem reported presenting their real self on Facebook to a greater extent" (p.1).

Nevertheless, even with the different aspects of self, social media platforms can encourage false self-presentation, which is damaging as explained by false-self theories (Winnicott, 1960). The false self-presentation happens mostly because many people would want to present the best part of their lives. A face that is smiling and for teenage girls that is painted with make-ups. Rarely would people want to share their low moments. When adolescents present the best part of their lives, those that are facing hardships and that cannot afford a "posh" lifestyle may be tempted to present a false self to keep to the standard of their friends, or they can look at how their friends look and because they cannot keep-up, their happiness is decreased and their psychological problems are heightened (Winnicott, 1960). Gil-Or, Levi-Belz, and Turel (2015), in a study that consisted of 258 Facebook users, argued that the use of Facebook and other social media platforms can promote the false presentation of the self. They showed that users with low self-esteem and low trait authenticity were more likely than others to present a Facebook-self which deviated from their true selves.

The false self is so suspicious and defending that it can lead an adolescent to risky behaviors (Baker \& McNulty, 2013) such as showing affection and asking for support. For adolescents to establish and keep close relationships, they require to engage in behaviors that impress their friends. Additionally, as they impress their peers, they may use social media exceedingly which may result in internet addiction (Turel, He, Xue, Xiao, \& Bechara, 2014). Mwadime (2015) in Kenya found out that teenagers spend their time online via smartphones or computers, in an attempt to create a positive impression. Meier and Gray (2013) exploring how Facebook use influences adolescent girls' body image, suggested that it is not the amount of time spent on Facebook that brings about body image disturbance but possibly the amount of time devoted to profiling updating, and editing of photos and the social comparison. They disclose personal information through personal profiles trying to express who they are (Junco, 2014; Gosenell, Britt, \& Mckibben, 2012; Yang \& Brown, 2016) and so they self-disclosure by revealing detailed personal information to others (Jourard \& Lasakow, 1959; Davis, 2012). Some researchers have reported that some adolescents use online self-disclosure to overcome loneliness and to facilitate their feelings of social connectedness (Bonetti, Campbell, \& Gilmore, 2010; Olenik-Shemesh, Heiman, \& Eden, 2012; Davis, 2012). However, in a longitudinal study carried out by McDool, Powell, Roberts, and Taylor (2016) between 2010 and 2014 from the UK among student teenagers 10 to 15 -year old, proposed that an enormous time spent on social media decreases the fulfillment adolescent experience in every area of their lives, a statement supported by Margalit (2010).

\section{STUDY DESIGN AND METHODS}

The study used a descriptive survey design to enable the researcher to understand the effects of social media interaction on adolescents' self-presentation. Descriptive survey design enabled the use of a representative sample of a large population within a short time (Mutai, 2000), with limited resources. The study took place among high school students in Nairobi County.

\section{Sampling Procedures and Sample Size}

The population targeted herein was all 89 public high schools in Nairobi County, with a total population of 51843 students. The sampling procedure ensured a true representation of the entire population. Therefore, stratified random sampling was done, whereby the 89 secondary schools were divided into three strata. The desired sample size was obtained proportionately from each stratum. To calculate the proportion of students from each stratum, stratified sample formula (sample size of the strata $=$ size of the entire sample divided by the population size, multiplied by the total of each stratum). Then the sample of each stratum was added up to make the sample size. The sample size was 400 respondents. Simple random sampling was then done to obtain students in each of the sampled schools.

\section{Data Collection Instrument, Procedure, and Ethical Consideration}

The survey instrument included: a questionnaire that had questions on students' use of social media platforms, and the self-presentation scale adapted from Michikyan et. al., (2014) with permission. Examples of the statements that are part of the self-presentation scale are "I sometimes try to be someone else on social media", "I compare myself to others on social media platforms", among others. The survey instruments sought for information on social media interaction and students' evaluation of their self-presentation. A pilot study was done to ensure the questionnaire covered important concepts and it was well understood by the respondents. To measure the internal consistency of each construct, the items on social media interaction were subjected to Cronbach's coefficient test and obtained $\alpha$ of .73. The researcher informed the respondents about the purpose of the study and guaranteed them confidentiality before administering the questionnaires. The questionnaires were administered during break time to ensure there were no classes interrupted. The questionnaires took between 20 and 25 minutes to fill in. 
The researcher obtained permission to carry out the study from the research authorization bodies including government research agency, the Ministry of Education, and the school Principals. Parental consent was obtained before engaging the respondents in the study. All the information received was kept confidential and was only available to the researcher. Statistical Package for Social Sciences (SPSS) was used to help generate descriptive statistics, that is, means and percentages, as well as inferential statistics, i.e., regression.

\section{FINDINGS}

The study aimed to investigate the effect of social media interaction on high school students' self-presentation. Descriptive statistical tests were performed to show the students' self-presentation. Regression analysis was done to predict whether social media interaction had a significant effect on high school students' self-presentation.

\section{Social Media Interaction on Self-Presentation}

The research question of the study was to identify the effect of social media interaction on students' self-presentation. The hypothesis of the test was, Ho1: "The social media interaction has no significant effect on high school students' selfpresentation". To test for this hypothesis, descriptive statistical tests were performed to show the students' self-presentation. Regression analysis was employed to predict the effects of social media interaction on self-presentation.

\section{Descriptive Statistics for Self-presentation}

On descriptive, the mean and standard deviation were applied to show the spread of the response. The mean value of 4.5 represented SA, the mean value of 3.5 to 4.4 represented Agreed, the mean value of 2.5 to 3.4 represented Neutral, the mean value of 1.5 to 2.4 represented Disagreed and lastly, the mean value of 1.4 represented Strongly Disagreed. The findings were presented in table 1.

Table 1: Mean and Standard Deviation for Self-presentation

\begin{tabular}{|c|c|c|c|c|c|c|c|}
\hline & Mean & Std. Deviation & SD & $\mathrm{D}$ & $\mathrm{N}$ & A & SA \\
\hline $\begin{array}{l}\text { I like myself, proud of what I want, stand for it and } \\
\text { show it }\end{array}$ & 3.65 & 1.248 & 9.2 & 9.0 & 18.2 & 33.8 & 28.9 \\
\hline $\begin{array}{l}\text { Have a sense of what I want, so I express my views } \\
\text { and beliefs }\end{array}$ & 3.53 & 1.223 & 9.0 & 11.6 & 19.1 & 36.1 & 22.5 \\
\hline $\begin{array}{l}\text { I have a good sense of self, shown by things I do } \\
\text { on social media }\end{array}$ & 3.49 & 1.233 & 10.1 & 9.8 & 20.8 & 35.0 & 21.1 \\
\hline $\begin{array}{l}\text { whom I want to be is often reflected in the things I } \\
\text { do on my SM profile }\end{array}$ & 3.45 & 1.370 & 12.4 & 15.6 & 15.0 & 28.6 & 28.3 \\
\hline $\begin{array}{l}\text { The way I present myself on social media is how I } \\
\text { am in real life }\end{array}$ & 3.40 & 1.303 & 11.3 & 15.3 & 18.8 & 30.9 & 23.1 \\
\hline $\begin{array}{l}\text { I post things on my SM platforms to show aspects } \\
\text { of whom I want to be }\end{array}$ & 3.38 & 1.325 & 11.8 & 15.9 & 18.5 & 29.5 & 24.3 \\
\hline $\begin{array}{l}\text { I change my photos on my profile to show different } \\
\text { aspects of who I am }\end{array}$ & 3.21 & 1.345 & 15.0 & 17.3 & 17.3 & 30.6 & 18.8 \\
\hline Who I am online is similar to who I am offline & 3.20 & 1.358 & 15.9 & 17.1 & 15.3 & 32.4 & 18.2 \\
\hline $\begin{array}{l}\text { I can try-out many aspects of who I am on SM } \\
\text { much more than in real life }\end{array}$ & 3.20 & 1.308 & 14.2 & 16.2 & 20.5 & 30.1 & 17.1 \\
\hline $\begin{array}{l}\text { I only show the aspects of myself on SM that I } \\
\text { know people would like }\end{array}$ & 3.16 & 1.410 & 19.4 & 14.2 & 16.3 & 29.8 & 19.4 \\
\hline $\begin{array}{l}\text { I am a completely different person online than I am } \\
\text { offline }\end{array}$ & 2.95 & 1.468 & 24.9 & 17.1 & 11.8 & 28.0 & 17.1 \\
\hline I sometimes try to be someone else on social media & 2.85 & 1.476 & 27.7 & 17.1 & 12.4 & 26.0 & 15.9 \\
\hline $\begin{array}{l}\text { I feel I have many sides to myself and I show it on } \\
\text { my SM profile }\end{array}$ & 2.60 & 1.255 & 23.7 & 26.9 & 21.4 & 19.7 & 7.5 \\
\hline I try to impress others on social media platforms & 2.42 & 1.452 & 40.2 & 17.6 & 13.0 & 16.5 & 11.8 \\
\hline $\begin{array}{l}\text { I compare myself to others on social media } \\
\text { platforms }\end{array}$ & 2.29 & 1.418 & 42.5 & 19.4 & 9.5 & 16.5 & 9.5 \\
\hline $\begin{array}{l}\text { I post information about myself on my social } \\
\text { media that is not true }\end{array}$ & 2.21 & 1.342 & 43.4 & 22.8 & 11.3 & 14.7 & 7.8 \\
\hline
\end{tabular}


The findings show that majority of the respondents agreed with the following statements: 'I like myself and am proud of what I want, I stand for and I show it on my social media profile' $(\mathrm{M}=3.65, \mathrm{SD}=1.248)$; ' I have a sense of what I want in life and using social media is a way to express my views and beliefs' $(\mathrm{M}=3.53, \mathrm{SD}=1.223)$; and 'I have a good sense of self that is shown by things I do on social media' $(\mathrm{M}=3.49, \mathrm{SD}=1.233)$. The majority of the respondents seemed undecided in their opinion on the following statements: 'Whom I want to be is often reflected in the things I do on my social media profile' $(\mathrm{M}=3.43, \mathrm{SD}=1.365)$; 'The way I present myself on social media is how I am in real life' $(\mathrm{M}=3.40, \mathrm{SD}=1.303)$; 'I post things on my social media platforms to show aspects of whom I want to be' $(\mathrm{M}=3.37, \mathrm{SD}=1.325)$; 'I change my photos on my profile to show different aspects of who I am' $(\mathrm{M}=3.21, \mathrm{SD}=1.345)$; Who I am online is similar to who I am offline' $(\mathrm{M}=3.20, \mathrm{SD}=1.358)$; 'I can try-out many aspects of who I am on social media much more than in real life' $(\mathrm{M}=3.20, \mathrm{SD}=1.308)$; 'I only show the aspects of myself on social media that I know people would like' $(\mathrm{M}=3.15, \mathrm{SD}=1.411)$; 'I am completely different person online than I am offline' $(\mathrm{M}=2.96, \mathrm{SD}=1.470)$; and 'I sometimes try to be someone else on social media' $(\mathrm{M}=2.85, \mathrm{SD}=1.476)$.

However, the majority of the respondents disagreed with the following statements: 'I feel I have many sides to myself and I show it on my social media profile' $(\mathrm{M}=2.60, \mathrm{SD}=1.255)$; 'I try to impress others on social media platforms' $(\mathrm{M}=2.41$, $\mathrm{SD}=1.452)$; 'I compare myself to others on social media platforms' $(\mathrm{M}=2.29, \mathrm{SD}=1.418)$; and 'I post information about myself on my social media that is not true' $(\mathrm{M}=2.21, \mathrm{SD}=1.345)$.

Most of the students indicated that they liked themselves and were proud of what they stood for and showed it on social media platforms. Implying the interactions of these students were intentionally directed towards self-promotion and trying to look friendly and nice to peers. It could also mean they had fulfilling relationships with peers and so there was a lesser struggle to impress them. Several students were undecided about their opinions. Implying they cared about how others viewed them but were not intentional on the self-presentation strategy they were employing to impress others. A few respondents disagree that they had a different aspect of self, they tried to impress others, they compared themselves with others, and posted information about themselves that was not true on social media platforms. This implies that self-presentation is more indirect in identity exploration. There is a possibility that students did not do self-presentation deliberately, their self-presentation was triggered without their conscious awareness that they were editing photos, updating status, to impress others.

\section{Effect of Social Media Interaction on Self-presentation}

The linear regression model was chosen to answer the study hypothesis, $\mathrm{H}_{0} 1$ : "The social media interaction has no significant effect on high school students' self-presentation". The first output of the linear regression model used to predict the effect of social media interaction on the self-presentation was displayed in table 2.

Table 2: Model Summary of Social Media Interaction on Self-Presentation

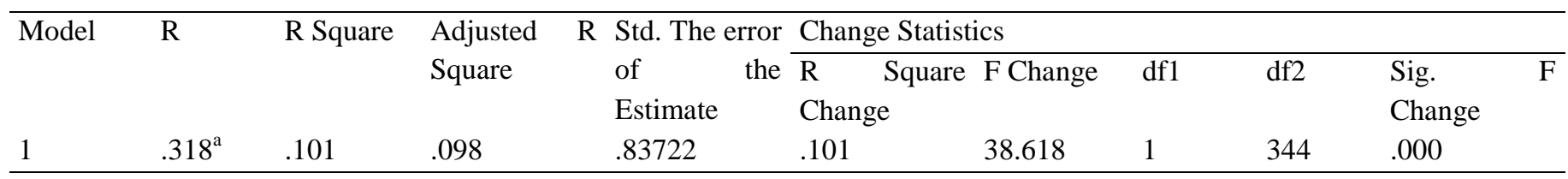

a. Predictors: (Constant), social media interaction

The model was significant $\mathrm{F}(1,344)=38.618$, p-value $<.05$. Further, the R Square $\left(\mathrm{R}^{2}\right)=.101$ shows $10.1 \%$ of students' self-presentation can be attributed to social media interaction. ANOVA tests on linear regression were used to determine if the regression model used to answer the hypothesis was fit to determine the predictor other than using the mean comparison. From the ANOVA, the regression model was suitable for predicting the outcome variable since the equation was significant $\mathrm{p}<0.05$ as indicated in table 3.

Table 1: Regression ANOVA of Social Media Interaction on Self-presentation

\begin{tabular}{lllllll}
\hline Model & & Sum of Squares & $\mathrm{df}$ & Mean Square & $\mathrm{F}$ & Sig. \\
& Regression & 27.068 & 1 & 27.068 & 38.618 & $.000^{\mathrm{b}}$ \\
1 & Residual & 241.121 & 344 & .701 & & \\
& Total & 268.189 & 345 & & & \\
\hline
\end{tabular}

a. Dependent Variable: Self-Presentation

b. Predictors: (Constant), social media interaction

The coefficient model of social media interaction on self-presentation was presented in Table 4. 


\section{International Journal of Research in Social Science and Humanities (IJRSS)}

DOI: doi.org/10.47505/IJRSS.2020.9145
E-ISSN : 2582-6220

Volume 1, Issue 4

Sep-Oct - 2020

Table 2: Coefficients of Social Media Interaction on Self-presentation

\begin{tabular}{lllllll}
\hline Model & & \multicolumn{2}{l}{ Unstandardized Coefficients } & $\begin{array}{l}\text { Standardized } \\
\text { Coefficients }\end{array}$ & $\mathrm{t}$ & \multirow{2}{*}{ Sig. } \\
\cline { 3 - 5 } & & $\mathrm{B}$ & Std. Error & Beta & \\
\multirow{2}{*}{1} & (Constant) & 1.386 & .218 & & 6.348 & .000 \\
& Social media interaction & .362 & .058 & .318 & 6.214 & .000 \\
\hline
\end{tabular}

a. Dependent Variable: Self-Presentation

The coefficient of the self-presentation based on the students' social media interaction shows the regression weight was statistically significant $(p<.05)$. The output showed social media interaction affects students' self-presentation $(\beta=.318, t=$ $6.348, p<.05$ ) hence an increase of social media interaction increases the students' self-presentation by .318 .

Therefore, the null hypothesis of study: $\mathrm{H}_{0} 1$ : "the social media interaction has no significant effect on high school students' self-presentation," was rejected. The alternate hypothesis $\mathrm{H}_{1} \mathrm{a}$ : "the social media platforms interactions have a significant effect on high school students' self-presentation" was accepted. Meaning there was enough evidence to support the alternative hypothesis. The social media platform interaction predicts self-presentation. An increase in social media interaction increases the self-presentation of the students, though at a minimal rate.

Most of the respondents agreed that students modified their photos to look like their friends. The respondents admitted doing photoshop, editing the photo, and sending them to friends to see their reaction. They said they cared how they looked before their friends on the platforms. The respondents' desire is their friends to acknowledge that they are cool in their looks. Most probably their self-presentation was influenced by the "stars" they were following on social media platforms. They emulate the 'stars', and in the process copy their styles, including their physical appearance i.e., their make-ups and their body shape. The majority do photoshop, modify the photo by improving on the shape, background effect, and color, to appear superb; then send it to the social media groups. They post the photos and eagerly wait for the 'likes' and comments from friends. Editing the photos enable adolescents to hide some aspects about themselves while enhancing what they want others to see. Mehdizadeh, (2010) supported the claim that people post information about themselves and exaggerate phases of their lives to make them seem more interesting and happier than others.

With the increased use of social media platforms, adolescents are virtually becoming obsesses with their appearance, and so they frequently update their status, share videos in the public domain for appraisal. The study was consistent with the findings of Wong (2012) who found that Facebook interaction with friends had a strong positive relationship with self-presentation. However, Vries et al (2016) found that increased social media interaction predicted increased dissatisfaction with body image. The results imply that students seek positive feedback that makes them popular and so boosts their ego and in turn keeps them motivated to interact on social media platforms. Therefore, students' body appearance and positive feedback on social media platforms play a crucial role in the development of self-identity.

\section{CONCLUSION OF THE DISCUSSION}

The researcher found out that social media interaction affected high school students' self-presentation. The results showed that social media interaction had significant effects on high school students' self-presentation. The study was consistent with the findings of Wong (2012; Meier \& Gray, 2013) who found that Facebook usage as interaction with friends had a strong positive relationship with self-presentation. The present study found that adolescents try to impress others on social media platforms though at times unconsciously. Possibly because they want to establish and nurture their large connections, so they are inclined to creating profiles and photos of highly stylized self-images. Rui \& Stefanone (2013) stated that adolescents with large networks have increasing demands for relationship maintenance, which results in increased photo sharing. In their attempt to make positive self-images of themselves, they may fail to remain authentic. 
Adolescents constantly liken the ways they present themselves with other people on social media platforms to authenticate their views, attitudes, and values. They use the feedback they receive to evaluate their selves, and this may affect their self-image positively or negatively and in turn their self-presentation. Like what Leary and Kowalski (1990) stated that selfpresentation affects self-esteem and well-being because of the feedback adolescents receive on social media platforms. Some adolescents may act completely different online from the persons they are offline. It could be they are shy of face-to-face interactions and the anonymity of the social media platforms influence their interactions. Studies found that online self-disclosure help adolescents overcome loneliness and facilitate their feelings of social connectedness (Bonetti, Campbell, \& Gilmore, 2010; Olenik-Shemesh, Heiman, \& Eden, 2012; Davis, 2012). The positive response of feedback can lead to social media behavior like increased usage of Facebook (Meshi, Morawetz, \& Heekeren, 2013). Desire to make positive impressions is part of what makes adolescents spend a lot of time on social media platforms. They use much of their time changing pictures and information about themselves on social media platforms to present to others their most appealing self.

\section{Implications for the Study}

Social media platforms are becoming a part of adolescents' lives and are increasingly advancing, and therefore their impact cannot be ignored. Adolescents' desire to present a positive self-image may lead them to use much of their time and effort editing and updating profile status. They may end up using different social media platforms to obtain content or photos that they edit to achieve the desired post. They may take numerous selfies, select, and edit to appear more attractive than what they are, and then posted on the social media platforms. They may compare their lives with those of other adolescents who are displaying their lavish lifestyles, valuing themselves against their peers. This may lead them to monitor their appearance and any slight dissatisfaction with their body may result in low self-esteem. The nature of social media interaction such as photo sharing, content editing, receiving like and many more may drive adolescents to present their ideal appearance. All this happens as they try to seek self-identity. Future research should be carried out using longitudinal research methods to determine whether social media interaction push adolescents to use the platforms more for self-presentation.

\section{RECOMMENDATIONS}

This article intended to share the findings with parents, teachers, youth workers, and policymakers for them to gain insights on how adolescents' use of social media platforms affect their self-presentation. After understanding how social media affects adolescents' self-presentation, it is important to have seminars and workshops to educate the parents, teachers, and youth workers on these effects. The researcher further recommends education programs to help educate adolescents to use social media platforms in ways that are beneficial to their self-identity. These include education programs on how to protect their privacy by ensuring the information they disclose on these platforms is well-thought-out and relevant to the audience. As some may provide their story in entirely because they are influenced by the anonymity on social media platforms. It is also expected that discussions will be held to ensure there are clear policies on online child safety and protection.

There is a need to sensitize adolescents on the risks associated with social media interaction. Social media facilitate the widening up of a network of friends. This is because an individual may end up connecting with hundreds of friends through the networks of other friends. The more connections one has, the riskier it might be depending on the information that an individual present on social media platforms. Information put on social media last long and may affect their identity later.

There are several limitations to the study and the findings must be understood in this context. First, the variables were measured through self-report. Adolescents could have been biased when reporting on their own experiences driven by the desire to report what is socially acceptable. Second, the Likert scale was used. Probably the rating scale was limiting or inexact leading adolescents to give an extreme or in-between response to all questions. Third, the respondents were high school students mainly from public schools in Nairobi County. Future studies should include private schools and should be replicated in rural areas as Nairobi County is mainly a metropolitan city. Fourth, the descriptive survey design used in this study is limiting to inferential statistics. Therefore, there is a need to do longitudinal studies, and other studies in the future need to use other research methods that can be used for advanced inferential statistics.

\section{CONCLUSION}

Social media is essential for adolescents in establishing and maintaining social contacts and experimenting with identity as it provides unlimited opportunities and great freedom on self-presentations. These platforms provide an opportunity for selfpresentation to adolescents just as they do in a face-to-face environment. This article presented information regarding social media interaction effects on the self-presentation of adolescents in high schools. Adolescents seek to make impressions as they establish and maintain social connections. Interactions on through established connections on social media platforms provide feedback to adolescents' comments, posts, photos, videos among other content, which adolescents evaluate to shape their self-presentation. The self-presentation is affected by the feedback adolescents receive, negative feedback may. These may influence the amount of time they use on social media platforms and the number of contacts they establish, the kind of content they are exposed to as they interact with others locally and internationally. 


\section{International Journal of Research in Social Science and Humanities (IJRSS)}

DOI: doi.org/10.47505/IJRSS.2020.
E-ISSN : 2582-6220

Volume 1, Issue 4

Sep-Oct - 2020

\section{REFERENCES}

Baumeister, R. F. (1998). The self. In the Handbook of Social Psychology, 1, 2, $4^{\text {th }}$ edition, eds., D. T Gilbert, S.T. Fiske, and G. Lindzey. New York, NY: McGraw-Hill, 680-740.

Baumeister, R. F. (1982). Self-esteem, self-presentation, and future interaction: A dilemma of reputation. Journal of Personality, 50 (1) 29-45. Available at https://doi.org/10.1111/j.1467-6494.1982.tb00743.x

Baumeister, R. F. \& Hutton D. G. (1987). Self-presentation theory: Self-construction and audience-pleasing. In B. Mullen et al (eds.), Theories of Group Behavior. New York: Springer-Verlag Inc.

Baker, L. R., \& McNulty, K. J. (2013). When low self-esteem encourages behaviors that risk rejection to increase interdependence: The role of relational self-control. Journal of Peers Social Psychology, 106(6): 995-1019. DOI: $10.1037 / \mathrm{a} 0032137$.

Bonetti, L., Campbell, M. A., \& Gilmore, L. (2010). The relationship between loneliness and social anxiety with students' and adolescents' online communication. Cyberpsychology, Behavior, and Social Networking, 13 (3): 279-285.

Chua, T. H., \& Chang, L. (2016). Follow me and like my beautiful selfies: Singapore teenage girls' engagement in selfpresentation and peer comparison on social media. Computers in Human Behavior, 55, 190-197.

Davis, K. (2012). The tension of identity in a networked era: young people's perspectives on the risks and rewards of online selfexpression. New Media and Society, 14 (4): 643-651.doi:10.1177/1444811422430.

Gabriel, F. (2014). Sexting selfies and self-harm: young people, social media, and the performance of self-development. Media International Australia, 151(1): 104-112.

Gilbert, D. T., Fiske, S. T. \& Lindzey, G. (Eds.). (1998). The handbook of social psychology, $4^{\text {th }}$ ed., volume 1. New York: McGraw-Hill Companies, Inc.

Gil-Or, O., Levi-Belz, Y., and Turel, O. (2015). The "Facebook-self": Characteristics and psychological predictors of false selfpresentation on Facebook. Frontiers in Psychology. DOI: 10.3389/fpsyg.2015.00099

Goffman, E. (1959). The presentation of self in everyday life. New York: Anchor Books.

Gosenell, C. L., Britt, T. W., \& Mckibben, E. S. (2012). Self-Presentation in Everyday life: effort, closeness, and satisfaction. Self and Identity, 10(1): 18-31. http://doi,org/10.1080/15298860903429567.

Higgins, T. E. (1989). Self-discrepancy theory: What patterns of self-beliefs cause people to suffer? In L. Berkowitz (Ed.), Advances in experimental social psychology (vol. 22, pp.93-136). New York: Academic Press.

Ho, Lee, \& Liao. (2016). Social network sites, friends, and celebrities: The roles of social comparison and celebrity involvement in adolescent's body image dissatisfaction. Journal of Social Media and Society. DOI: 10.1177/2056305116664216.

Jones, E. E., \& Pittman, T. S. (1982). Toward a general theory of strategic self-presentation. In J. Suls (Ed.), Psychological Perspectives on the Self (Vol.1, pp. 231-262). Hillsdale, NJ: Erlbaum.

Junco, R. (2014). Social media and student identity development. excerpted from engaging students through social media: evidence-based practices for use in student affairs. Available at www.josseybass.com/highereducation.

Jourard, S. M., \& Lasakow, P. (1959). Some factors in self-disclosure. Journal of Abnormal and Social Psychology, 56(1): 91-98.

Kleemans, M., Daalmans S., Carbaat, I., \& Anschutz, D. (2018). Picture perfect: the direct effect of Manipulated Instagram Photos on Body Image in Adolescent Girls. Media Psychology, 21(1): 93-110. Available at https://doi.org/10.1080/15213269.2016.1257392.

Leary, M. R. (1995). Self-presentation: Impression management and interpersonal behavior. Madison, WI: Brown \& Benchmark.

Leary, M. R., \& Kowalski, R. M. (1990). Impression management: A literature review and a two-component model. Psychological Bulletin, 107(1): 34-47

Livingstone, S., \& Haddon, L. (2009). EU Kids Online: Final Report. From http://www.lse.ac.uk/media@1se/research/EUKids/Online/EU\%20Kids\%201\%20(2006-

9)/EU\%20Kids20Online\%201\%20Report/EUKidsOnlineFinalReport.pdf.

Margalit, M. (2010). Lonely students and adolescents: self-perceptions, social exclusion, and hope. New York: Springer.

Mehdizodeh, S. (2010). Self-presentation 2.0: Narcissism and self-esteem on Facebook. Cyberpsychology, Behavior, and Social Networking, 13(4): 357-364.

Meier, E. P., \& \& Gray, J. (2013). Facebook photo activity is associated with body image disturbance in adolescent girls. Cyberpsychology, Behavior, and Social Networking, 10(10):1-8. Mary Ann Liebert, Inc. Doi: 10.1089/cyber.2013.0305

Meshi, D., Morawetz, C., \& Heekeren, H. R. (2013). Nucleus accumbency response to gains in reputation for the self relative to gains for others predicts social media use. Frontiers in Human Neuroscience, 7, 439. 
Metzler, A., \& Schelthauer, H. (2017). The long-term benefits of positive self-presentation via profile pictures, number of friends, and the initiation of relationships on Facebook for adolescents' self-esteem and the initiation of offline relationships. Relationships. Frontiers in Psychology, 8(1981): 1-15. Doi: 10.3389/fpsyg.2017.01981 from www.frontiersin.org

McDool, E., Roberts, J., Powell, P., \& Taylar, K. (2016). Social media use and students' wellbeing. Discussion Paper Series IZA DP No. 10412, IZA Institute of Labor Economics. Available at www.IZA.org.

Michikyan, M., Dennis, J., \& Subrahmanyan, K. (2014). Can you guess who I am? real, ideal, and false self-presentation on Facebook among emerging adults. Emerging Adulthood, 3 (1): 55-64. DOI. 10.117/21676696814532442.

Mutai, B. K. (2000). How to write quality research proposal: a complete and simplified recipe. Nairobi, Kenya: Egerton University.

Mwadime, E. K. (2015). An Investigation on the impact of online social networking on academic performance among high school students in urban areas: A case study of Westland Sub-County, Nairobi. University of Nairobi, MA unpublished thesis.

Olenik-Shemesh, D., Heiman, T., \& Eden S. (2012). Cyberbullying victimization in adolescence: relationships with loneliness and depressive mood. emotional and behavioral difficulties, 17(3): 361-374. DOI: 10.1080/13632752.2012.7004227.

Patchin, J. W., \& Hinduja, S. (2010). Changes in adolescent online social networking behaviors from 2006 to 2009. Computers in Human Behavior, 26(6): 1818-1821. Doi: https://doi.org/10.1016/j.ch.2010.07.009.

Perloff, R. M. (2014). Social media effects of young women's body image concern: theoretical perspectives and an agenda for research. Sex Roles, 71, 363-377. Doi 10.1007/s11199-014-0384-6

Rui, J. R., \& Stefanone, M. A. (2013). Strategic Image Management online. Information, Communication \& Society, 16(8): 12861305. DOI: 10.1080/1369118X.2013.763834. Taylor \& Francis, https://doi.org/10.1080/1369118X2013.763834

Schachter, E. P. (1986). The self and social life. New York: McGraw-Hill.

Schlenker, B. R. (1980). Impression management: Self-concept, social identity, and interpersonal relations. Monterey, CA: Brooks/Cole.

Steijn, W. M. P. (2014). A development perspective regarding the behavior of adolescents, young adults, and adults on social network sites. Cyberpsychology 8, 2 .

Turel, O., He, Q., Xue, G., Xiao, L., \& Bechara, A. (2014). Examination of neural systems sub-serving Facebook "addiction." Psychol Rep Psychological Reports, 115(3): 675-695.

Valkenburg, P. M., \& Peter, J. (2011). Online communication among adolescents: an integrated model of its attraction, opportunities, and risks. Journal of Adolescent Health, 48: 121-127. Doi: 10.1016/jjadohealth.2010.08020

Vohs, K., Ciarocco, N. J., \& Baumeister, R. (2005). Self-Regulation and Self-presentation: Regulatory resources depletion impairs impression management and effortful self-presentation depletes regulatory resources. Journal of Personality and Social Psychology. DOI: 10.1037/0022-3514.88.4.632-source: PubMed

Vries, D. A. Peter, J., Graaf \& Nikken, P. (2016). Adolescents' Social network sites use, peer appearance related feedback, and body dissatisfaction: Testing a mediation model. Journal of Youth and Adolescence, 45, 211-224.

Walrave, M., \& Heirman, W. (2012). Predicting teenagers' involvement in privacy management strategies on social network sites. International Communication Association, 1-34.

Winnicott, D. W. (1960). Ego distortion in terms of a true and false self. The maturational processes and the facilitating environment, ed. D. W. Winnicott. New York: International University Press.

Wong, W. K. (2012). Faces on Facebook: a study of self-presentation and social support on Facebook. Discovery- Social Studies Student E-Journal, 1, 184-214.

Yang, C., \& Brown, B. (2016). Online self-presentation on Facebook and self-development during the college transition. Journal of Youth Adolescence, 45, 402-416.

Zhao, S., Grasmuck, S., \& Martin, J. (2008). Identity construction on Facebook: digital employment in anchored relationships. Computers in Human Behavior, 24 (5): 1816-1836. DOI: 10.1016/j.chb.2008.02.01.

*Correponding Author: jesywambo@gmail.com 